\title{
Experimental studies on model scramjet in a Mach 6 high enthalpy free-jet wind tunnel
}

\author{
X.Y. Chang, L.H. Chen, H.B. Gu, and G. Yu \\ Laboratory of High Temperature Gas Dynamics, Institute of Mechanics, Chinese Academy of \\ Sciences, Beijing 100080, China
}

\begin{abstract}
A side-wall compression scramjet model with different combustor geometries has been tested in a propulsion tunnel that typically provides the testing flow with Mach number of 5.8 , total temperature of $1800 \mathrm{~K}$, total pressure of $4.5 \mathrm{MPa}$ and mass flow rate of $4 \mathrm{~kg} / \mathrm{s}$. This kerosene-fueled scramjet model consists of a side-wall compression inlet, a combustor and a thrust nozzle. A strut was used to increase the contraction ratio and to inject fuels, as well as a mixing enhancement device. Several wall cavities were also employed for flame-holding. In order to shorten the ignition delay time of the kerosene fuel, a little amount of hydrogen was used as a pilot flame. The pressure along the combustor has an evident raise after ignition occurred. Consequently thrust was observed during the fuel-on period. However, the thrust was still less than the drag of the scramjet model. For this reason, the drag variation produced by different strut and cavities was tested. Typical results showed that the cavities do not influence the drag so much, but the length of the strut does.
\end{abstract}

\section{Introduction}

Scramjet engine as a high performance propulsive system for hypersonic vehicles has been investigated for last half century[1-6]. Although several engine flight tests have been conducted in past few years, the main studies are still performed on the ground tests. Due to the high flow speed passing through the engine, hence, short residence time of air and fuel in a limited length combustor, mixing, ignition and flame-holding became dominated issues in scramjet design and development. Many attempts were made on the optimizations and improvements of such mechanisms related to mixing enhancement, self and forced ignition, and flame stabilization by using struts, ramps, steps, cavities, plasma touches and their combinations[7-12]. Beside the engine characteristic studies, the developments of experimental facility and technique are also important issues for the scramjet research. However because of the extremely complicated mechanism of scramjet, a complete theory or a design handbook has not been published. Therefore, the accumulation of the scramjet works will make up a database available for engineering design and development.

In order to study the fundamental phenomena of scramjet, several important issues such as mixing enhancement, ignition, flame stabilization and liquid fuel atomization were experimentally studied with a direct-connected supersonic combustion facility that simulates the combustor of a scramjet since middle of 90's in IMCAS (Institute of Mechanics, Chinese Academy of Sciences) [13-18]. Based on the results obtained, a scramjet model has been designed and tested in a high enthalpy free-jet tunnel that provides nominal Mach number 5.8, total temperature $2000 \mathrm{~K}$, total pressure $5 \mathrm{MPa}$ and mass flow rate $4 \mathrm{~kg} / \mathrm{s}[19,20]$.

The present work focused on the thrust performance and the drag influence of the side-wall compression scramjet model. The effects of strut and cavities acting on the thrust and drag were experimentally investigated. 


\section{Descriptions of experimental setup and scramjet models}

\subsection{Test facility}

The test facility used in the scramjet experiments is a high-enthalpy free-jet tunnel, so-called HPTF (Hypersonic Propulsion Test Facility). It consists of a vitiated air generator, a supersonic nozzle, a test cabin, an ejector exhaust and a silence tower, as shown in Fig.1. Additionally, a computer programmed time sequence control system and a data acquisition system have been developed[19-20]. It provides typical test conditions as Mach number 5.8, total pressure 5MPa, total temperature $2000 \mathrm{~K}$ and mass flow rate $4 \mathrm{~kg} / \mathrm{s}$ by a rectangular facility nozzle with the exit of $300 \mathrm{~mm}$ in width and $187 \mathrm{~mm}$ in height. The pressure of $4 \mathrm{kPa}$ inside the test cabin which duplicates the engine entrance pressure condition of $25 \mathrm{~km}$ altitude can be achieved by a singlestage triple-nozzles air ejector with $40 \mathrm{~kg} / \mathrm{s}$ mass flow rate.

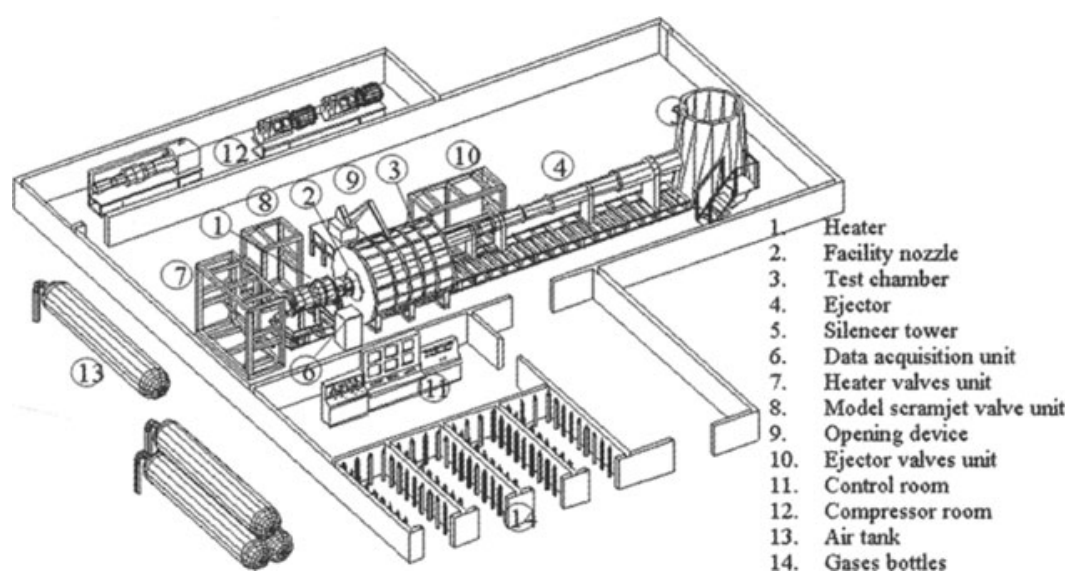

Fig. 1. Schematic of HPTF tube

The uniformity of the facility nozzle flow was validated by a scanning water-cooled pitot rake with 16 pressure ports in $2 \mathrm{~cm}$ interval driven by a computer-controlled lead screw. The iso-Mach number contour was calculated by using the ratio of the total pressure measured in the heater to the pressure measured by the pitot rake. The Mach number of the core flow was distributed among 5.7 to 5.8 as shown in Fig.2. The dashed square in the figure shows the inlet entrance projection plane of the typical side-wall compression scramjet model.

\subsection{Side-wall compression scramjet model}

The model, so-called SCM03, used in the tests was designed with strut/cavity integrated configuration for mixing enhancement and combustion stabilization. The contraction ratio of the inlet, $474 \mathrm{~mm}$ in length and $70 \mathrm{~mm}$ in height, is 6.25 with counting the strut thickness. An isolator following the inlet is $100 \mathrm{~mm}$ long with 0.5 degree half divergent angle. The combustor is $800 \mathrm{~mm}$ long with a 1.5 degree half divergent angle. The thrust nozzle is $300 \mathrm{~mm}$ long and has expansion ratio of 1.7 . The blockage ratio of the model to the facility nozzle is $31 \%$. The strut having staggered wedge tail serves as compression surface at the inlet as well as a fuel injector in the combustor. Recessed cavities functioning as flameholder in the combustor were used. Both strut and cavity generate variant vortexes that help the mixing and combustion process, as well as extending the fuel residence time. The fuel for scramjet model was kerosene. A small amount 


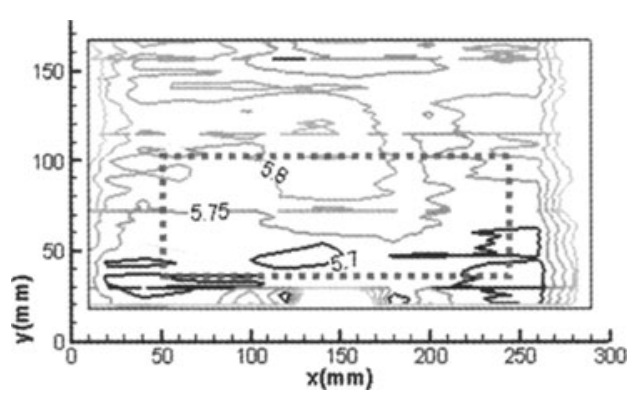

Fig. 2. Iso-Mach number contour at the facility nozzle exit plane

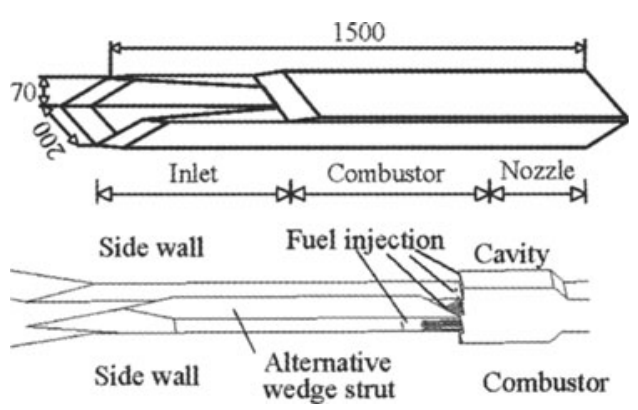

Fig. 3. SCM03 model and strut/cavity details

of hydrogen was also introduced into the combustors working as pilot flame to help the kerosene ignition.

\section{Results and discussions}

The typical testing flow conditions for the present experimental series were $1650-1750 \mathrm{~K}$ in total temperature, $4-4.5 \mathrm{MPa}$ in total pressure, $3.8-4.2 \mathrm{~kg} / \mathrm{s}$ in mass flow rate, and 5.8 in Mach number, respectively.

\subsection{Pressure distributions along scramjet models}

Fig.4 shows the pressure distributions along the scramjet model with different cavities. The open and solid marks in the figure represent the state before and after ignition respectively. LS and $\mathrm{D}$ in the figure means the long strut $(800 \mathrm{~mm})$ condition and the depth of cavities. The length/depth ratio was kept at 7.5 when the depth was changed. The numbers after the $D$ are the depth of the cavities in millimeter. Consequently D0 means that no cavity was used. In cases of D12, D6 and D0, the cavities did not show any influence on the inlet flowfield before the ignition. However the pressure distributions along the combustor showed that the different cavities gave some effects on the wave system before the ignition.

The pressure distributions in the figure also showed that kerosene fuel was successfully ignited and stably burned for all three cases. It was evident that the deeper cavity makes bigger contribution to the combustion, resulting in the higher pressure distribution. But the cavity is not an absolute necessary condition to burn the kerosene fuel. As shown in the figure, even in D0 case, the combustion still occurred, although the pressure distribution was not as high as the cavity cases.

\subsection{Thrust and drag acting on scramjet models}

Fig. 5 is the time passage of the forces acting on the model with and without cavity $(\mathrm{D}=12 \mathrm{~mm}$ and $\mathrm{D}=0 \mathrm{~mm}$ ) during the test run. The ejector started to work at $\mathrm{t}=0 \mathrm{~s}$ making a big drag to the model due to its pump effect. Following the air in the test chamber pumped by the ejector, the drag got a stable level during $t=1.4-3.5 \mathrm{~s}$. After the facility nozzle working on at $t=3.5 \mathrm{~s}$, the drag was observed again. Then an evident thrust was measured at $t=6 s$, when the model fuel-on. During the combustion process, the thrusts in both $\mathrm{D}=12 \mathrm{~mm}$ and $\mathrm{D}=0 \mathrm{~mm}$ cases kept a almost stable level until the fuel was shutdown at $t=8 \mathrm{~s}$. The thrust increments were $360 \mathrm{~N}$ for the non-cavity case and $440 \mathrm{~N}$ for the $\mathrm{D}=12 \mathrm{~mm}$ cavity case. It means that the cavity certainly improves the thrust performance. 


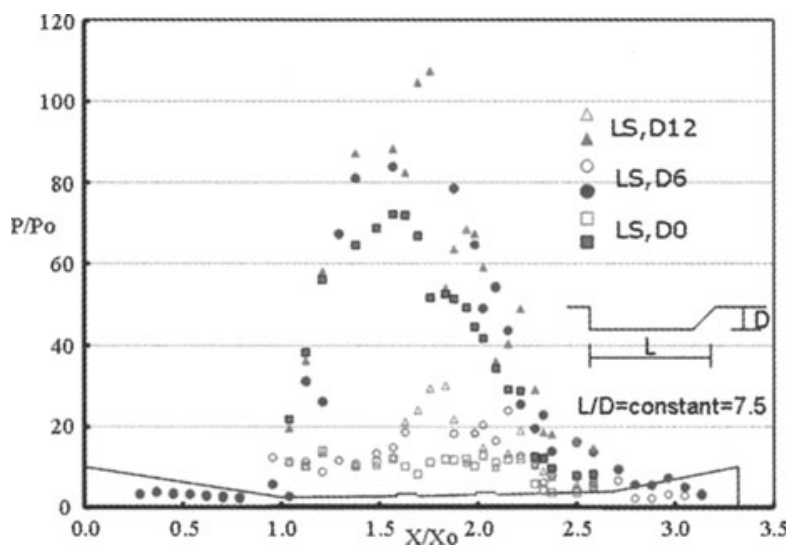

Fig. 4. Pressure distributions along the model before and after ignition

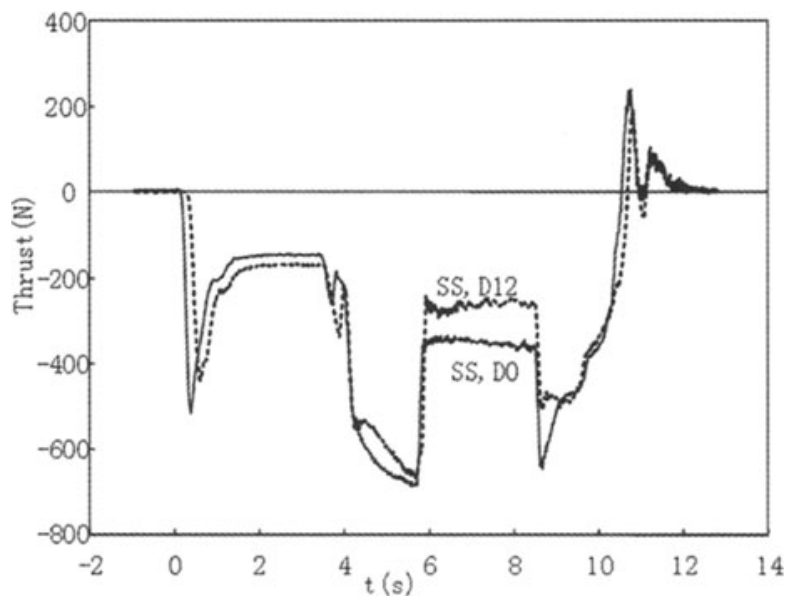

Fig. 5. Thrust and drag acting on the model

\subsection{Drag comparisons of different cavities and struts}

In order to improve the thrust performance of a scramjet, beside the increasing the combustion performance, the drag reduction also plays an important role. Fig. 6 shows a comparison between the different strut and cavities. SS and SM represent the short strut with length of $400 \mathrm{~mm}$ and short scramjet model with length of $1.5 \mathrm{~m}$, respectively. The drag coefficient in the figure shows the drag measured normalized by the dynamic pressure and the projection area of the model. Comparing the drags of the model with long strut and different depth of cavity, points (LS,D6) and (LS,D12), the drag coefficient of the D12r cavity was only $0.5 \%$ higher than D6 cavity. The D12 cavity was also only $0.8 \%$ higher than non-cavity case, by comparing the points (SS,D12) and (SS,D0), in same short strut case. These facts mean that the cavity geometry does not effect the drag so much.

On the other hand, the drag coefficient of the longer strut was $5.4 \%$ higher than shorter strut case, by comparing the points (LS,D12) and (SS,D12) with same cavity conditions. It is also interesting to compare the points (SS,D12) and (SS,D12(SM)). The drag coefficient of the longer scramjet model with the combustor length of $900 \mathrm{~mm}$ was $14.5 \%$ higher than shorter model with 


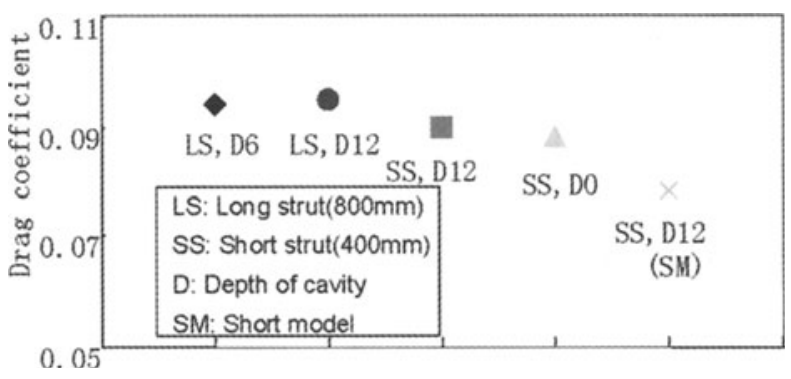

Fig. 6. Comparisons of the drag coefficient

the combustor length of $700 \mathrm{~mm}$. It means that the drag from the wet surfaces of the inner duct of the scramjet makes big effect on the scramjet engine performance.

\section{Conclusions}

Base on the side-wall compression scramjet model, the experimental results showed that the ignition and flameholding was not so sensitive to cavities. Even in non-cavity case, the ignition and combustion were also observed in the present experiments. However the cavities play an important role in improving the combustion and thrust performances. The drug coefficient variation caused by different cavities in the present studies was less than $1 \%$. On the other hand, the wet surface of the inner duct of the scramjet model produced lager drag.

\section{References}

1. G.L. Dugger: ARS Journal 29, 819 (1959)

2. R.J. Weber: American Society, 875 (1959)

3. R.A. Gross, W. Chinitz: Journal of the Aerospace Sciences 27, 517 (1960)

4. A. Ferri, P.A. Libby, V. Zakkay: In: Proceedings of the International Council of the Aeronautical Sciences, Third Congress, (1962)

5. E.S. Shchetinkov: In: 7th. Intern. Symp. on Combustion, 1958, pp.583-589

6. R. Marguet, Ch. Huet: Optimal design of a fixed geometry ramjet using subsonic then supersonic combustion from Mach 3 to Mach 7, ONERA TP No.656 (1962)

7. B. Debout, C. Mathieu: Franch PREPHA program, status report. AIAA Paper 92-5107 (1992)

8. A. Yoshida, H. Tsuji: AIAA J 15, 463 (1977)

9. T. Mitani et al.: Experimental validation of scramjet nozzle performance, AIAA Paper 923290 (1992)

10. R. Walther, W. Koschel, V. Sabelnikov, Y. Korontvit, V. Ivanov: In: International Symposium on Air Breathing Engines, ISABE 97-7085 (1997)

11. A. Ferri: Aeronautics and Astronautics 2, 32 (1964)

12. Anon: HREP - phase $\mathrm{n}$ - structures assembly model test data report, NASA CR-111993 (1971)

13. G. Yu, J. Li, J. Zhao, S. Yang, C. Li: Experimental studies on H2/air supersonic combustion. AIAA-96-4512 (1996)

14. G. Yu et al.: Hydrogen-air supersonic combustion study by strut injectors. AIAA-98-3275 (1998)

15. J. Li, G. Yu, X. Zhang, Q. Huang: Combustion of kerosene in a supersonic stream. AIAA2000-0615 (2000) 
16. G. Yu, J. Li, X. Chang, L. Chen, C.J. Sung: Journal of Propulsion and Power 17, 1263 (2001)

17. G. Yu, J. Li, X. Zhang, L. Chen, B. Han, C. Sung: Combustion Science and Technology 174, $1(2002)$

18. G. Yu, J.G. Li, L. Yue, J. Zhao, X. Zhang: Characterization of kerosene combustion in supersonic flow using effervescent atomization. AIAA-2002-5225 (2002)

19. X. Chang, L. Chen, G. Yu, D. Qian: Development of a facility for model scramjet testing. AIAA-2001-1857, (2001)

20. X. Chang, L. Chen, G. Yu: Design and tests of the diffuser system for an open-jet scramjet test facility. AIAA-2002-5240 (2002)

21. W.H. Heiser, D.T. Pratt: Hypersonic Airbreathing Propulsion, Chapter 6, AIAA Education Series, AIAA (1994) 